\title{
INVESTIGATING FACTORS AFFECTING READING COMPREHENSION, PERCEPTIONS OF READING TASK-TYPES AND STRATEGIES
}

\author{
To Thi Ngoc Huyeni, \\ Khau Hoang Anh \\ Tra Vinh University, \\ Vietnam
}

\begin{abstract}
:
Reading can be a crucial skill in studying a language as it helps record a plethora of knowledge in the world. Reading can be an entertaining activity or it can be a task. This study aims at investigating the task as this is commonly seen in studying a language. More specifically, the study targets three different objectives and 30 first-year English majors were recruited to answer the survey questions. They were asked about the factors that they thought to have the greatest effects on reading comprehension. The second section asked them about their opinion about difficult reading comprehension task-types. The third section elicited their opinion about reading comprehension strategies which they thought to be difficult to apply in doing comprehension tasks. The results revealed that most of the participants posited that they had obstacles in vocabulary, grammatical structures and unfamiliarity of the topic and vocabulary was seen as the most problematic. Then, grammatical structures were seen as the second most difficult. Furthermore, they thought that true/false questions, sentence completion questions; tasks like summary/table completion; and multiple-choice questions hindered them from understanding the reading comprehension tasks. Next, guessing the meaning from the context was found to be the most difficult strategy while spotting the specific information to answer the questions was seen as the second difficulty. Some limitations of the study were also concluded.
\end{abstract}

Keywords: reading comprehension, factors, reading comprehension task-types, reading comprehension strategies

\section{Introduction}

In recent years, Vietnam has become one of the members of many international organizations in the world such as World Trade Organization in 2007. Therefore, English

' Correspondance: email thnhuyen@tvu.edu.vn 
demand is also increasing. However, English ability is not the Vietnamese's strength in comparison with many other nationalities. Although the population of Vietnam is over ninety million, the number of people who can use English is not many. Most of them just speak their mother tongue and acquiring English is becoming tough. This can be one of the reasons Vietnam hardly attracts foreign investors. For that reason, the education program administered by the Minister of Education and Training has been innovated over time and English is seen as an important foreign language that needs improving. In fact, English has been known as one of the most significant foreign languages in Vietnam. It is also a compulsory subject at public schools and children begin to study English at an early age. At present, the learning of English has become a trend. More and more international schools, as well as educational institutions, have been established in Vietnam to create a variety of new opportunities for Vietnamese citizens to learn English to satisfy their professional development.

Additionally, the current labor market is also demanding English. It is one of the necessary factors affecting employers' career promotions. If the employees have a good English background, it is easy for them to find potential jobs. Therefore, improving English ability is an urgent mission, especially for those who work in foreign companies and international organizations.

In order to achieve a fruitful result in learning English, students first need to be proficient at all four skills (listening, speaking, reading and writing). Each skill has specific demands and difficulties. However, according to many English learners reading is seen as one of the most important and difficult skills. Ahmadi et al. (2013) stated that reading comprehension plays an important role in the process of learning a foreign or second language and it must be accentuated in different parts of the process. In addition, reading playing a key role in the instruction of all academic skills has a predictive feature concerning students' academic performances. Reading is a necessary skill not only in learning a language but also in daily life. Since childhood, children have been taught a list of alphabets in order to familiarize them with acquiring knowledge through reading because most of the knowledge is presented in the written form. Reading is useful in many aspects of human's life. For instance, people can read to relax, communicate, study or obtain information and the like. As a result, reading is considered an important means for people to communicate with one another in society and the world at all times.

As reading can be treated as for pleasure and comprehension, this research is restricted to investigating how English majors think about doing reading comprehension in terms of factors influencing reading comprehension ability, difficulties in using strategies to deal with reading comprehension questions and difficulties of reading comprehension task-types. The results of this study can be used to refer back to how reading comprehension is practiced in the classroom and how students do such kinds of exercises in and outside the classroom. 


\section{Literature review}

Since this paper aims to investigate how a group of English majors think of reading comprehension, the authors would like to describe it and related factors related to it first. Reading comprehension is defined as the ability to recognize the meaning of the reading text through consideration of context and knowledge. Grammar, knowledge of morphology, syntax, ability to recognize context, metacognition, ability to identify and predictability are required factors in readers (Hudson, 2007). In addition, reading comprehension requires the delicate interaction of several component processes that integrate information from the page that the student is reading with his or her background knowledge and experience, subject to a multitude of contextual constraints (Kintsch \& Kintsch, 2005). In detail, according to Snow (2002), "reading comprehension can involve the process of simultaneously extracting and constructing meaning through interaction and involvement with written language" (p. 11). Reading and reading comprehension are two different concepts. While reading is defined as the ability to use eyes to observe words and signal the brain to identify and decode words into sounds, reading comprehension is a more complex process required. The reader must understand the meaning of the text, the author's point of view, be aware of the message from a reading text (Afflerbach et al., 2008). Reading comprehension is a complex process including seeing, reading (by heart or vocalizing) and understanding (Rawson \& Kintsch, 2005).

Hsueh-Chao and Nation (2000) stated that knowledge of vocabulary and reading comprehension has a close relationship. In particular, this is a two-way correlation relationship. Knowledge of vocabulary can affect reading comprehension and reading comprehension can change vocabulary ability as well. Besides, according to Akbari (2014), as soon as the learner learns how to manipulate the syntax structure while reading a text, their understanding is greatly promoted. As seen, reading comprehension plays an important role in studying, working and in daily life. In studying, reading comprehension is a crucial skill because most of the knowledge is presented by the text. If someone wants to get to know something, they have to be able to read. In other words, it does not matter which subject they learn, they always need to read first. Especially, reading for understanding plays an integral part in education and becomes increasingly essential as learners progress from "learn to read" to "read to learn" (Jacobs, 2008). Additionally, Priebe et al. (2012) found that prior knowledge of the passage topic significantly increase fluency and reduce reading errors, especially errors based on graphic information, in poor readers. Many previous studies have investigated this topic and the authors would like to pick up many of the studies related to this investigation.

Karakoç and Köse (2017) investigated the relationship between vocabulary and reading comprehension and to do this they employed 175 students studying intensive language program in Turkey. The result of the study revealed that students' receptive vocabulary knowledge was larger than their productive vocabulary knowledge. Especially, the lexical level of the student essays and the students' productive vocabulary knowledge were significantly related. 
Gersten et al. (2001) explored if teaching reading comprehension strategies to students was effective. First, they described the factors that led to reading comprehension difficulties. Then, they described their procedures for reviewing the literature. Finally, they reviewed the studies involving instructional methods for improving reading comprehension ability. The author found this teaching was effective. For instance, many factors affecting reading comprehension were seen, such as strategic processing and metacognition, knowledge of common text structures, vocabulary knowledge, prior knowledge, reading fluency, active reading, and task persistence. To continue this influence, Ouellette (2006) measured the role of vocabulary in word reading and reading comprehension. This study aimed to better explain the role of vocabulary in various reading skills and it was interesting when the author led us to think of vocabulary breadth knowledge and vocabulary depth knowledge. Concurrent analyses revealed that each distinct reading skill was related to the vocabulary measures in a unique manner. Receptive vocabulary breadth was the only oral vocabulary variable that predicted decoding performance after controlling for age and nonverbal intelligence. In contrast, expressive vocabulary breadth affected visual word recognition, whereas the depth of vocabulary knowledge affected reading comprehension. Then, Chou (2011) also studied the effects of vocabulary knowledge and background knowledge on the reading comprehension of Taiwanese EFL Students. The author investigated 159 students from a college in Southern Taiwan. The study uncovered that the vocabulary factor was considered the most significant one in helping students understand the reading passages while background knowledge did not do much in helping improve reading comprehension in longer, more difficult passages. Likewise, Zhang (2012) explored the roles of vocabulary and grammar knowledge in second language reading comprehension using structural equation modeling analysis. This study recruited 190 participants at college and the result disclosed that vocabulary knowledge was regarded to be the most related significant factor to boost reading comprehension; grammatical knowledge to be the weak contribution to reading comprehension.

\section{Methodology}

\subsection{Research questions}

With the aim to help students enhance their ability to do reading comprehension tasks in English, the authors purposed to discover how first-year English majors think about reading comprehension. However, this topic seems too broad, so this study just focuses on answering the three following questions:

1) What factors do first-year English majors think to affect reading comprehension ability?

2) What reading comprehension task type do they think is the most difficult?

3) What reading comprehension strategies do they think are difficult to use? 


\subsection{The participants}

In this study, the data was collected from 30 first-year English majors who are from two different classes in their second semester at university. They are following a four-year undergraduate program in English. Before that, they had experience in doing reading comprehension tasks in their high school set by the Vietnamese Ministry of Education and Training. Their ages range from 18 to 19 and all of them speak Vietnamese as their first language.

\subsection{Research instrument}

In the current study, the data were collected by using a questionnaire. The questionnaire is used because it is an easy and popular way to get information from the participants. By using the questionnaire, the authors could design and organize possible questions regarding the requirement of the study's aims. Another benefit of using questionnaires in this study was saving time. The students were required to tick at the content that they thought were difficult for them in doing reading comprehension tasks.

\subsection{Research procedures}

The process of collecting necessary data for the research lasts for a long period because it is not easy to conduct a survey. In order to ensure that the survey takes place smoothly, the process of designing the questionnaire and finding the participants must be carefully prepared. The research data collecting process is carried out in three main phases. The first one was designing the survey questionnaire. The questions were developed based on the definitions described in the second section of this study and based on the authors' own views and experiences. This process took two weeks. The second phase was conducting the survey. The questionnaire was delivered to a group of 30 students during their break time. It took them about 10 minutes to complete the questionnaire. After they had finished the tasks, they sent their responses back to the authors. The third phase was the data analysis. The information obtained from the survey was processed in a week, using the Statistical Package for Social Sciences (SPSS software), looking for the frequency of the responses.

\section{Findings and discussion}

\subsection{Findings}

The process of inputting and processing the data in SPSS took 3 days. After this process, the necessary information obtained from the questionnaire of the study is described in this section.

The first subsection to be presented here is the result of the first research question. "What factors do first-year English majors think to affect reading comprehension ability?" 
Table 4.1: Factors affecting reading comprehension

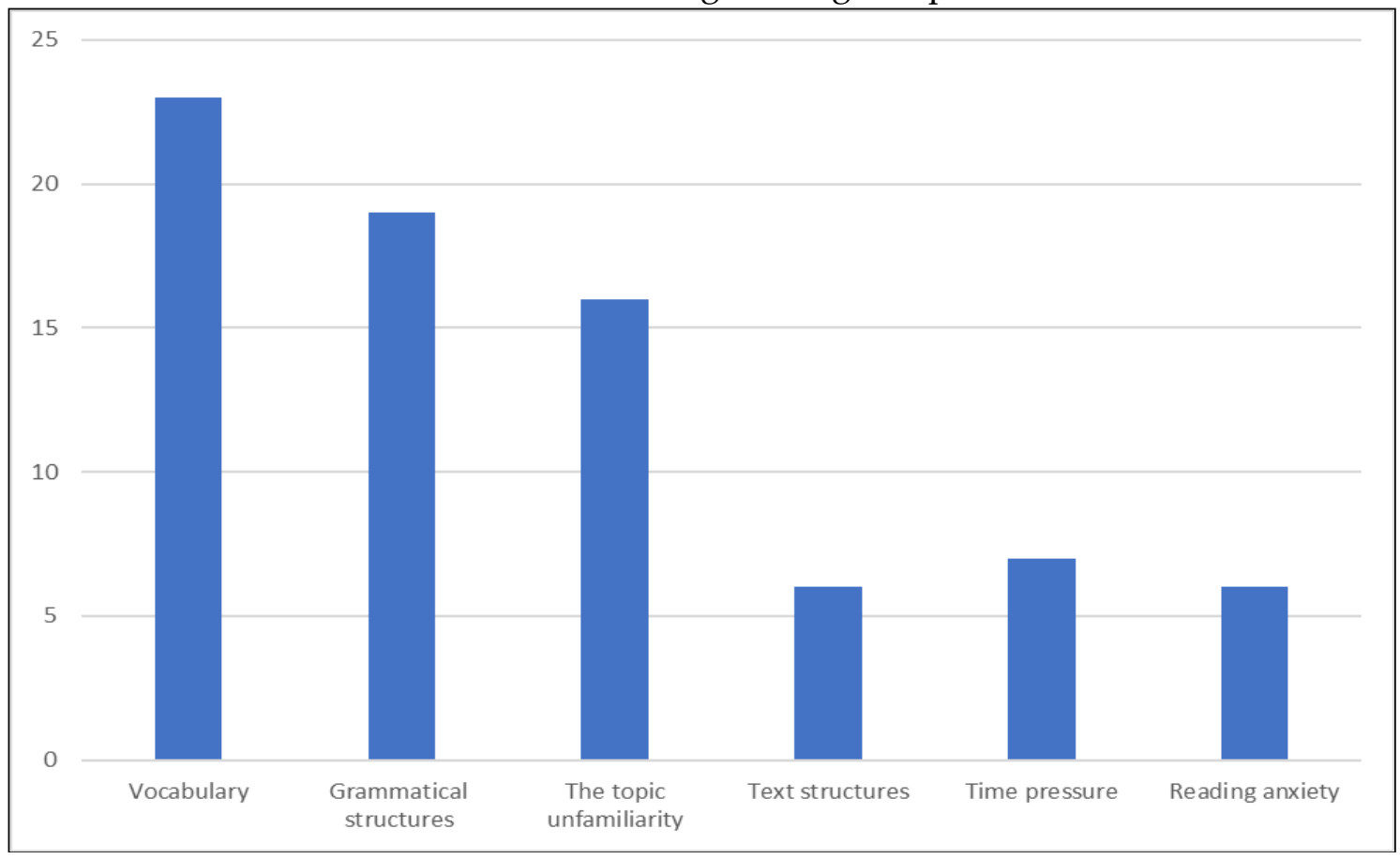

For this question, the authors found that the students have many problems with the vocabulary factor because this statement was the most chosen. Specifically, up to twenty-three people in a total of thirty participants agreed that they meet difficulties in vocabulary when doing reading comprehension. In other words, $76.7 \%$ of the participants encounter plenty of obstacles related to vocabulary. Next, the grammatical structure element is also the problem of many participants. Nineteen students indeed selected this statement, making up $63.3 \%$. Following this was the unfamiliarity of topics. For this factor, as can be seen, sixteen students were content that topic familiarity is crucial for lessening difficulties in doing reading comprehension, constituting 53.3\%. Next, only seven participants $(23.3 \%)$ believed that time pressure is one of the causes affecting reading comprehension. Finally, the number of students considering text structure and reading anxiety as their difficulties when reading was the same, including six agreements (20\%). Overall, the data of this question illustrates that vocabulary is regarded as the most difficult factor for this group in doing reading comprehension. Besides, the grammatical structures and the unfamiliarity of the topic also caused the students much difficulty in doing reading comprehension.

The result of the second research question is illustrated in this subsection. "What the reading comprehension task-type do they think is the most difficult?" 
Table 4.2: Students' thinking of reading comprehension task-types

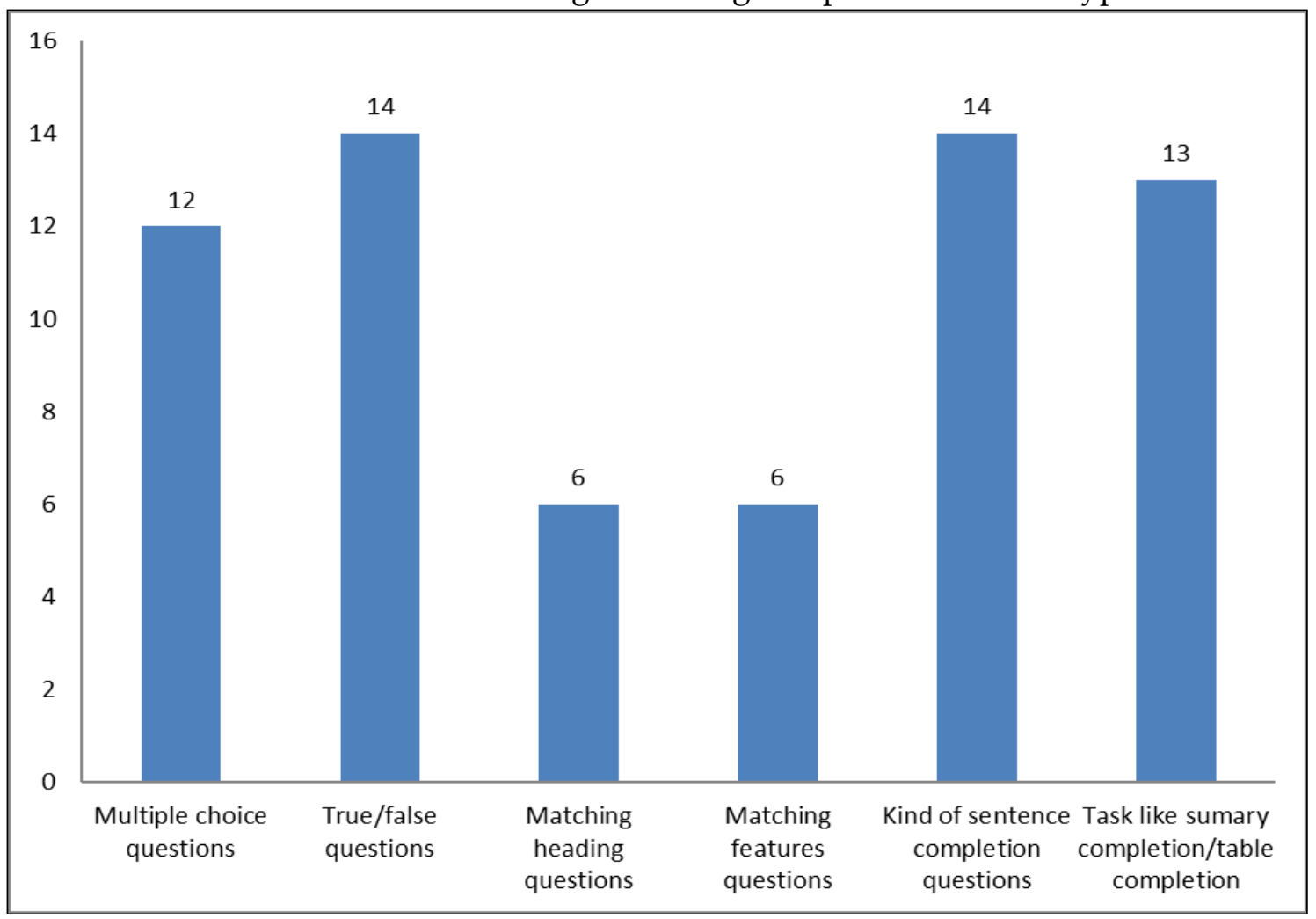

Table 4.2 illustrates how students think about reading comprehension task types. As seen in the data, most of the participants found it hard to answer true/false questions and kind of sentence completion questions. In fact, these two types of answer formats received the agreement of fourteen students (46.7\%). Next, thirteen participants (43.3\%) encounter many problems to overcome the tasks like summary completion/table completion. In much the same way, twelve participants $(40 \%)$ considered the multiplechoice question type as one of the most difficult question types. On the other hand, only six participants (20\%) expressed that matching heading questions and matching feature questions were hard to solve. In general, the data revealed that the most difficult tasktypes for first-year English majors are true/false questions and kind of sentence completion questions. Moreover, tasks like summary completion/table completion and multiple-choice questions are also very difficult.

This subsection is going to present the result of the third research question. "What reading comprehension strategies do they think are difficult to use?" 
Table 4.3: Students' thinking about reading comprehension strategies

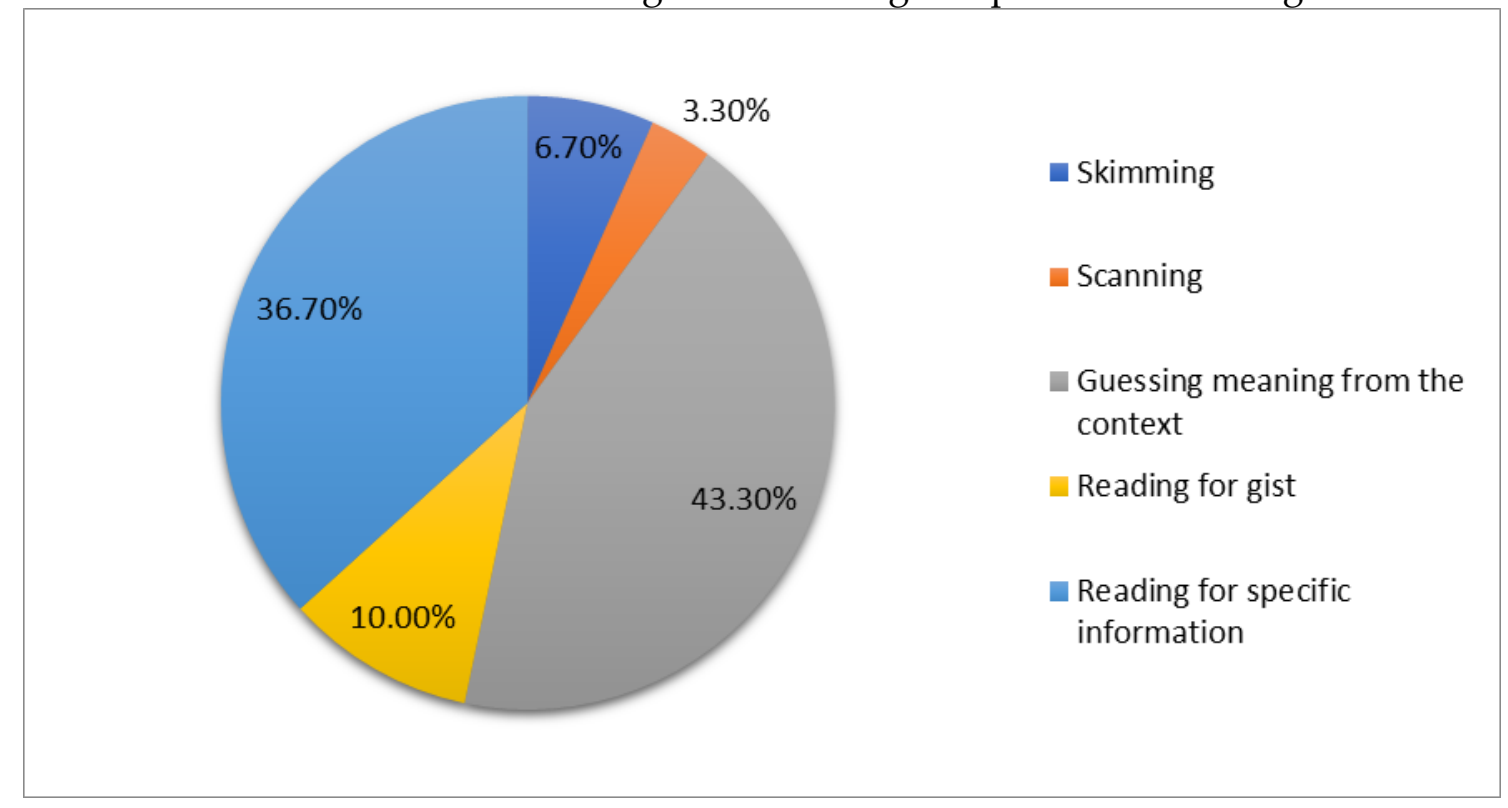

As can be depicted in Table 4.3, the authors found that guessing meaning from the context was rated as the most difficult strategy to use when doing reading comprehension. Up to thirteen participants (43.3\%) expressed that they were unable to guess the meaning from the context. Next, the students found reading for specific information to be the second most difficult strategy, accounting for $36.70 \%$ while only two participants $(6.7 \%)$ found it hard to apply skimming in doing reading comprehension. Similarly, scanning is a strategy that many students felt difficult to use. Only one person (3.3\%) agreed with this statement. Finally, only three participants (10\%) revealed that reading for gist was seen as the most difficult strategy to use when doing reading comprehension.

\subsection{Discussion}

To make it easier, the authors would like to discuss the results according to the order of the research questions.

First, vocabulary is found to be the most difficult factor affecting this group of students in doing reading comprehension. This finding is in line with Karakoç and Köse (2017); Ouellette (2006); Chou (2011) in that if students do not have a good vocabulary, they cannot read well. Hsueh-Chao and Nation (2000) stated that knowledge of vocabulary and reading comprehension has a close relationship. To illustrate, in the reading comprehension process, if students want to understand the ideas of a text, they first have to understand the meaning of vocabulary. For this reason, vocabulary plays a key role in reading comprehension. However, it is not easy to learn vocabulary, especially for English foreign learners because English vocabulary is very rich and numerous. As a consequence, it takes students a long time to build a large load of vocabulary knowledge. Furthermore, if students do not review it regularly, they may forget the learned words. Apart from the characteristics mentioned above, most of the participants in this study 
have limitations in vocabulary due to some reasons. First, when reading, they often ignore difficult words or use a dictionary instead of trying to guess the meaning of new words, brainstorming or getting the general idea of the text. Second, they do not have a habit of learning vocabulary or reviewing learned words. Finally, they spend little time learning vocabulary. In conclusion, vocabulary is still a typical problem in reading. Therefore, students should practice learning vocabulary often to improve their reading comprehension ability.

Standing behind vocabulary is the grammatical structure factor, which is considered as the second most difficult factor affecting this group of students in doing reading comprehension. Indeed, many students expressed that they are confused when meeting an unfamiliar grammatical structure when reading. Akbari (2014) also pointed out the importance of grammar in reading comprehension. For instance, when talking about an incident, if people use a passive sentence instead of the active sentence, it will show different meanings. Nonetheless, learning English grammatical structures is very hard. Although students in Vietnam are taught a lot of grammatical structures throughout their high school years, they still encounter many problems related to grammar. In addition, when reading, most students do not focus on analyzing grammatical structures. As a result, when meeting new grammatical structures in a reading text, students often ignore them and read without understanding.

The unfamiliarity of the topic is seen to be the third difficult factor influencing this group of students in doing reading comprehension. Many of the participants in this study confessed that they found it very hard to read a new theme text. In other words, each student is only good at a few topics. Besides, the research findings of Priebe et al. (2011) also verified the important role of prior knowledge in reading comprehension. However, students' background knowledge is limited while the reading topics are unlimited. Therefore, when reading unfamiliar topic texts, students usually cannot understand the meaning of specialized terms. For this reason, students should spend time reading newspapers and books because it is very good for them to widen their knowledge in many different fields.

The following section will discuss the reading comprehension task types. The result showed that true/false questions, sentence completion questions and tasks like summary completion/table completion and multiple-choice questions are the four most difficult task-types that first-year English majors encounter when doing a reading comprehension test. In fact, these question types are very popular and familiar to students. Each type of question has a specific way to do it and requires different skills. To illustrate, a multiple-choice question is choosing the correct answer for a question from several possible options. This type of question requires students to understand the information in the passage and scan for specific information. True/false question is deciding whether the information in the question statement can be found in the passage. Students need to identify specific information in the passage to answer the type of this question. Sentence completion question is completing the sentence by filling the gaps with words from the passage. In order to overcome this type of task, students should scan 
for specific information and select suitable words. Summary completion question is completing a summary by filling in the gaps using words from the passage or words given in a box. Students need to understand the ideas and supporting points to select suitable words. The table completion question is completing a table by using the correct in the passage. This task type requires students to understand detailed information to locate them in the passage to choose appropriate words. However, students are often lack strategies for each task type because they do not interest in analyzing task types after reading.

The last point for discussion is about difficulties in using reading comprehension strategies. Guessing meaning from the context was found to be the most difficult strategy to apply in doing reading comprehension tasks. This is easy to understand as many strange vocabularies are hard for students to guess. Thus, training students how to use prefixes and suffixes to guess new words can be plausible. In addition, exercises on guessing meaning from a known word in a different context can work. For instance, the word "interest" in "I have an interest in doing yoga" as in "I think that bank offers high interest" is a kind of this exercise. A student can know the closest meaning of "interest" in the first context and he or she will guess the meaning of this same spelling in the second context. Reading for specific information was also found to be challenging for this group of students to apply to doing reading comprehension tasks. It stands third place in this category. Hence, exercises like finding names of people and places can be best practice. Furthermore, exercises such as looking for dates and more specific objects can be used to practice such kind of strategy. However, time must be included here for concern. As known, in the test, test-takers usually do not have much time to interpret the meaning around the context.

\section{Conclusion}

Reading comprehension plays an important role in learning English but it is also one of the most difficult skills for students, especially for first-year English majors. For this reason, the present study has been conducted to investigate how first-year English majors think about doing reading comprehension. In order to attain the study's aim and have the results for the research, three questions were applied. The first question is about investigating factors affecting doing reading comprehension. The second question is exploring difficult task types in doing reading comprehension and the last question is investigating difficult strategies used in doing reading comprehension.

The final results of the study uncovered that when doing reading comprehension, a majority of first-year English majors meet difficulties in vocabulary, grammatical structures and unfamiliarity of the topic. Among these ones, vocabulary is seen as the most difficult factor causing reading comprehension much difficulty. Next, a large number of students confessed that they were worried about grammatical structures when doing reading comprehension. For task-types in reading comprehension, many first-year English majors found it hard to do true/false questions; sentence completion questions; 
tasks like summary/table completion; and multiple-choice questions. The mentioned task types are very familiar and they usually appear in students' reading comprehension tests. Finally, guessing meaning from the context was considered the most difficult strategy to use. Locating specific information to answer the questions was also seen as the second most difficult strategy to apply.

It is unavoidable to meet some limitations. Because of time limitations, the authors were unable to conduct a test to see how students perform a reading comprehension test. Therefore, this study can only use the data source from the questionnaire. Second, the study cannot fully reflect the difficulties of first-year English majors when doing reading comprehension. In fact, this topic is broad and the authors cannot cover a large sample of difficult factors, reading task-types and reading strategies. Therefore, more strategies, difficult factors and task-types used in reading comprehension should continue to be explored.

\section{Conflict of Interest Statement}

The authors declare no conflicts of interest.

\section{About the Authors}

To Thi Ngoc Huyen is a lecturer of English at the School of Foreign Languages, Tra Vinh University, Vietnam. She earned her Master's Degree in Principles and Methods in English Language Education at Can Tho University, Vietnam. Her interests include teaching methodology and translation.

Khau Hoang Anh teaches English at Tra Vinh University (the Head of English Department). He did his Master's in TESOL at California State University, Fullerton, USA. He has taught English to Vietnamese learners, especially undergraduates for more than 10 years. He has published many papers on foreign/second language education and translation. Currently, he is doing his doctorate degree in Bilingual Education at National Tsing Hua University, Taiwan.

\section{References}

Afflerbach, P., Pearson, P. D., \& David, S. G. (2008). Clarifying differences between reading skills and reading strategies. The reading teacher, 61(5), 364-373.

Ahmadi, M. R., Ismail, H. N., \& Abdullah, M. K. (2013). The Importance of metacognitive reading strategy awareness in reading comprehension. English Language Teaching, 6(10), 235-244.

Akbari, Z. (2014). The role of grammar in second language reading comprehension: Iranian ESP context. Procedia-Social and Behavioral Sciences, 98, 122-126.

Chou, T. P. (2011). The effects of vocabulary knowledge and background knowledge on reading comprehension of Taiwanese EFL Students. Electronic Journal of Foreign Language Teaching, 8(1), 108-115. 
Gersten, R., Fuchs, L. S., Williams, J. P., \& Baker, S. (2001). Teaching reading comprehension strategies to students with learning disabilities: A review of research. Review of educational research, 71(2), 279-320.

Hsueh-Chao, M. H., \& Nation, P. (2000). Unknown vocabulary density and reading comprehension. Reading in a foreign language, 13(1), 403-430.

Hudson, T. (2007). Teaching second language reading. Oxford: Oxford University Press.

Jacobs, G. (2008). We learn what we do: Developing a repertoire of writing practices in an instant messaging world. Journal of Adolescent $\mathcal{E}$ Adult Literacy, 52(3), 203-211.

Karakoç, D., \& Köse, G. D. (2017). The impact of vocabulary knowledge on reading, writing and proficiency scores of EFL learners. Journal of language and linguistic studies, 13(1), 352-378.

Kintsch, E., \& Kintsch, W. (2005). Comprehension. In children's reading comprehension and assessment (pp. 89-100). Routledge.

Ouellette, G. P. (2006). What's meaning got to do with it: The role of vocabulary in word reading and reading comprehension. Journal of educational psychology, 98(3), 554566.

Priebe, S. J., Keenan, J. M., \& Miller, A. C. (2012). How prior knowledge affects word identification and comprehension. Reading and writing, 131-149.

Rawson, K. A., \& Kintsch, W. (2005). Rereading effects depend on time of test. Journal of educational psychology, 97(1), 70-80.

Snow, C. (2002). Reading for understanding: Toward an RED program in reading comprehension. Rand Corporation.

Zhang, D. (2012). Vocabulary and grammar knowledge in second language reading comprehension: A structural equation modeling study. The Modern Language Journal, 96(4), 558-575. 
To Thi Ngoc Huyen, Khau Hoang Anh

INVESTIGATING FACTORS AFFECTING READING COMPREHENSION, PERCEPTIONS OF READING TASK-TYPES AND STRATEGIES

Creative Commons licensing terms

Author(s) will retain the copyright of their published articles agreeing that a Creative Commons Attribution 4.0 International License (CC BY 4.0) terms will be applied to their work. Under the terms of this license, no permission is required from the author(s) or publisher for members of the community to copy, distribute, transmit or adapt the article content, providing a proper, prominent and unambiguous attribution to the authors in a manner that makes clear that the materials are being reused under permission of a Creative Commons License. Views, opinions, and conclusions expressed in this research article are views, opinions, and conclusions of the author(s). Open Access Publishing Group and European Journal of Foreign Language Teaching shall not be responsible or answerable for any loss, damage, or liability caused in relation to/arising out of conflicts of interest, copyright violations, and inappropriate or inaccurate use of any kind content related or integrated into the research work. All the published works are meeting the Open Access Publishing requirements and can be freely accessed, shared, modified, distributed, and used in educational, commercial, and non-commercial purposes under a Creative Commons Attribution 4.0 International License (CC BY 4.0). 